\title{
THE PUNONG BARANGAY IN SOUTHERN NUEVA VIZCAYA: THEIR LEADERSHIP BEHAVIOR AND COMPETENCIES
}

\author{
Arcadia Alice T. Ordoñez, DPA \\ Nueva Vizcaya State University, College of Arts and Sciences \\ Bambang, Nueva Vizcaya, Philippines
}

Article DOI: https://doi.org/10.36713/epra9594

DOI No: $10.36713 /$ epra9594

\begin{abstract}
The Punong Barangay are agents of development in the national government and they play a vital role in the development and progress of our country through a strong barangay local government. The study conducted used the descriptive approach and utilized a validated survey instrument on leadership behavior and competencies. The cluster random sampling using the proportional allocation was utilized to gather data from 234 samples. The data analysis showed that the respondents were predominantly male, married, about 45 years old, high school graduates, with low annual income and with 5-9 dependents. Their leadership behavior and competencies were found as very satisfactory. There was no significant relationship between leadership behavior and profile variables. The study will serve as benchmarking reference to further improve punong barangays' leadership behavior and competencies for good local governance.
\end{abstract}

KEYWORDS: Punong Barangay, leadership behavior, and competencies

\section{INTRODUCTION}

Presidential Decree Number 86 issued on December 31, 1972 and the 1973 Constitution of the Republic of the Philippines, revived the barangay as the primate political units in the Philippine society. The Old Barangay system was revived in order to broaden the base of citizen participation in the democratic process and to afford ample opportunities for the citizenry to express their views on important local and national issues. The barangay which is a small, closely and interpersonally related groups, is hoped to draw out more responsive opinions and ideas from its members. The revival of the barangay may also awaken the interest of the people in the affairs of the government and in the conduct of their officials while the nation is re-directed towards consciousness, unity and involvement.

Orendain (1996) cited that every local government unit created or recognized under the Local Government Code is politic and corporate, endowed with powers to be exercised by it in conformity with laws. As such, it exercises powers as a political subdivision of the national government and as a corporate entity or corporation representing the inhabitants of its territory.

The approval of the Local Government Code of 1991 provided the barangays other powers which may be greater than what they already have. The Punong Barangay has more powers, relatively speaking, than the Mayor or Governor. The Punong Barangay is the chief executive exercising the basic duty of executing laws and ordinances applicable in the barangay. He exercises some legislative powers by being the presiding officer of the sangguniang barangay, thus participating in the consideration and passage of barangay ordinances. He participates in settling disputes by being the chairman of the "lupong tagapayapa". Although there are many limitations on barangay powers, the above observation is a consolation to the legal status of the barangay in the hierarchy of local government units.

Under the regime of President Aquino, the government is bent on changing the profile of the barangays as basic political units into agencies for economic growth and development in the countryside. Today, the barangay is not only an institution of "participatory democracy" but more significantly the eventual realization of real people's power. It is an evolving dynamic mechanism for democratic action in the attainment and promotion of community interest and goals.

Barangay Captains are also known as Punong Barangay or Barangay Administrators, and administrators are confronted by four major tasks. These tasks vary in a little way from organization to organization. These tasks are:

1. The Punong Barangay must fulfill the goals of the organization. 
2. The Punong Barangay must make use of other people in fulfilling these goals, not as if they were machines but rather in such a way as to release their initiative and creativity.

3. The Punong Barangay must also face the humanitarian aspect of his job. He wants people who work for him to be happy. This is morale - the idea that under suitable conditions people will do better work than they will under unsuitable conditions.

4. The Punong Barangay must try to build into his organization provisions for innovation for change and for development. In a changing world, people and organization must adjust to changing conditions. The conditions for change must be incorporated into organization so that these may become a steady process of development rather than a series of sudden disruptive innovations.

In this study, these tasks are used as vantage points and backdrop in viewing the leadership behavior of Punong Barangay in Nueva Vizcaya. According to House and Mitchell (1974: 65) there are four leadership behaviors. These leadership behaviors are:

1. Supportive Leadership is giving consideration to the needs of subordinates, displaying concern for their welfare, and creating a friendly climate in the work unit.

2. Directive Leadership is letting subordinates know what they are expected to do, giving specific guidance, asking subordinates to follow rules and procedures, scheduling and coordinating the work.

3. Participative Leadership is consulting with subordinates and taking their opinions and suggestions into account.

4. Achievement-Oriented Leadership is setting challenging goals, seeking performance improvements, emphasizing excellence in performance, and showing confidence that subordinates will attain high standards.

Santos (2007) and Aldaba (1997) as cited by Principe (2011) mentioned that the role of a leader is indispensable in an organization. Accordingly, the success or failure of an institution largely depends on the kind of administrator appointed to lead the institution. He is the very person who is expected to provide the members of the organization the vision and direction for the institution.

Similarly, Dumangeng (2002) as cited by Gamilde's (1996) disclosure that the leader sees things through the eyes of his followers, putting himself in their shoes and helping them make their drama come true and assumes that his followers are working with him, not for him, considers them partners in the work, sees to it that they share in the rewards and glories the team spirit.

Likewise, Sajo and Tabaldo (1993) conducted an empirical study among local chief executives in the province of Iloilo. They disclosed that an overwhelming majority of local executives have emphasized and practiced participatory management and teamwork in managing local government.

Tendero, (1993) takes into account the use of behavioral style and traits theory to fit the political culture of the society. Ferdinand E. Marcos adopted an autocratic style as a response to the deteriorating socio-economic and political condition in the country. Corazon Aquino, in her desire to restore democracy opted for participative leadership. The path President Fidel V. Ramos is pursuing is not very definite. While making an open pronouncement of "people empowerment", critics perceive signs of a veering toward authoritarian power exercise to accelerate the pace of development. Where to set the parameters of discretion and flexibility of the leader and the extent of the participatory role of the people are questions.

Leveriza (1986) also cited that leadership is the key to effective management of organizations. It establishes the dynamics between the leaders and his followers. It provides and sets the pace of performance of the organization. It further provides the direction as well as the inspiration that make people work willingly, enthusiastically, efficiently, and effectively.

Leadership is a subject that has aroused the interest of scholars and laymen as well. (Stogdill 1987), in his researches on leadership theories, points out that there can be as many definitions as there are people wanting to define the concept. Leadership can be regarded as an influence process, since a leader may be called upon to live a life demonstrating fullness of what he believes in, thus making him a good example for followers. Leadership occurs when one person influences another and convinces him to do a thing to achieve something. Influence may range from persuasion to the use of coercion to get things done. The ability to structure social interaction systems and accomplish what is proposed to be achieved, creates personality dynamics needed by one seeking leadership responsibilities.

As the barangay gains its new found social and political prominence, its rate of progress in general and the capacity of its people for growth in particular will find reflection in the leadership provided to them by its recognized leader - the Punong Barangay. The barangay, based on tradition, is an extended family where the leaders are on the a first-name basis with the community members whom they serve their constituency. Their role is mediator, conciliator, and adjudicator. The Punong Barangay are agents of development in the national government and they play a vital role in the development and progress of our country through a strong barangay local government.

It is along the foregoing perspective that the researcher is motivated to undertake further study on the leadership and competencies of punong barangay of the province of Nueva Vizcaya to validate the result of the previous study.

This will also serve as an aid of legislation of national policies relevant to the competencies, skills and abilities of the punong barangays, of their roles as element of change in the society and the efficient delivery of basic services to the public.

This research is an attempt to establish the profile, leadership behavior and competencies of Punong Barangays in the province of Nueva Vizcaya and its implications to the changing concept of local governance. Their being a service provider to that of a facilitator in order to provide better performance in performing their duties and functions as Punong Barangays. 
The research will provide first - hand information on the leadership behavior and competencies among Punong Barangay in the province of Nueva Vizcaya. The findings will serve as an eye opener to the people of Nueva Vizcaya to be a wise voter. Likewise, these findings will provide information on what technical assistance the local executives and the Department of Interior and Local Government could initiate in order to upgrade the profile of barangay captains in the province of Nueva Vizcaya.

Constituents expect to have good leaders, consequently, the immediate constituents' needs and aspirations would be identified and their frustrations could be known if they will be assessed on how they perceive. This will lead to a satisfying and harmonious relationship between the immediate constituents and the barangay captains. This will enhance participation in the barangay affairs.

\section{OBJECTIVES}

Specifically, this research is grounded on the following objectives which are aimed:

1. to identify the profile of the punong barangay in terms of age, sex, civil status, educational attainment and annual income;

2. to assess the punong barangay based on the perception of their constituents;

3. to identify the level of leadership behavior of Punong Barangay as assessed by themselves; and

4. to determine significant differences as perceived by the respondents along leadership behavior among punong barangay members when grouped according to their profile variables.

\section{Definition of Terms}

For a clearer understanding of the study, the following key variables are operationally defined:

Age refers to the age bracket of the respondent ranging from twenty four (24) to seventy (70)

Achievement-Oriented Leadeship Behavior refers to the style of leadership involves setting challending goals, seeking improvement in performance, and emphasizing excellence

Barangay refers to the smallest political subdivision or unit of the government which serves as the primary planning and implementing arm of government programs, projects and activities. It also serves as the place where the collective views of the people in the community are discussed and considered.

Barangay Captain refers to the head of the barangay government who is responsible in enforcing specific powers which are operative within the barangay.

Competencies refer to the special abilities, motives, traits, skills and personal attributes that are casually related to effective behavior. The competencies identified in this study are organizational ability, leadership interpersonal skills, work habits and attitudes.

Directive Leadership Behavior refers to the leaders behavior that provides guidance for subordinates by setting standards of performance, scheduling and coordinating work effort, and asking subordinates to follow rules and regulations

Educational Qualification is the highest educational degree attained by the subject.

In-Service Training refers to the trainings, seminars, workshops and programs attended by the subjects which are beneficial to them and to the organization, locally and internationally.

Local Government refers to the political subdivision of a nation or state constituted by law, which has substantial control over local affairs, including the power to impose taxes, the governing body of which is elected or appointed (Local Government Code, 1991).

Leadership is a process or act influencing the movements of an organized group in its efforts toward goal achievement (Hemphill and Coons, 1957: 7).

Leadership Behavior is the pattern of functions the administrator does which includes events, physical action, physiological and emotional processes and implicit mental activity which expresses his ability and readiness to inspire, guide, direct, or manage others (Good, 1959: 313).

Participative Leadership Behavior refers to a leader that solicits suggestions and advice from their subordinates and consider information from subordinates when making decisions.

Sex refers to the personal attributes of the respondent expressed in terms of his or her gender classification as masculine or feminine.

Supportive Leadership refers to a leadership behavior which is manifested by showing concern for the well being and personal needs of one's subordinates.

Transformational Leadership Behavior refers to the process of inspiring change and empowering followers to achieve greater heights, to improve themselves, and to improve organization processes, causing followers to accept responsibility and accountability for themselves.

Work Habits and Attitudes refers to the positive values toward work and the strong desire to improve oneself on the job. 


\section{II.METHODOLOGY}

The normative survey method was used in this study, specifically the descriptive survey method to gather information about current existing conditions. This method helped draw the profile and leadership behavior of Barangay Captains in Nueva Vizcaya. Three sets of questionnaire were used for gathering data, the personal data form, the competency scale and the leadership behavior scale was adopted from the book of Ordonez (1995)

The respondents in this research study consisted the Punong Barangay who were elected and qualified as of November, 2013 and the immediate constituents (Barangay Council). The cluster random sampling using the proportional allocation was utilized to gather data from 234 samples. The statistical procedure used were: the subject, frequency distribution, percentage and mean to describe the subject, one way analysis of variance (ANOVA) to test the significance of the differences between two or more means obtained from the independent samples. The $\mathrm{T}-$ test is generally used for comparison between two means while F-test is a parametric test used for comparision among three or more means.

\section{RESULTS AND DISCUSSIONS}

Demographic Profile of the Punong Barangay:

1. The age range of the subject Punong Barangay is 41 45. It could be speculated that most of the barangay captains are of middle age taking the life span of Filipinos at 60 years. It also reveals that $90 \%$ are males and only $10 \%$ are females which proves the societal expectations that men should be given preferential opportunity to occupy such political positions. The punong barangay reveals that $93 \%$ are married and $64 \%$ reach high school and only 5\% finished college, and the mean annual income seems to be rather low if they are married with 5-9 dependents to feed and support for their education.

Table1

\begin{tabular}{lcc} 
Weighted Mean Distribution of Responses of the Immediate Constituents & Among & Punong Barangay on Competencies \\
\hline Competencies & Mean & Qualitative Description \\
\hline Organizational Ability & 3.94 & Often \\
Leadership & 3.94 & Often \\
Personal Skills & 3.91 & Often \\
Work Habits and Attitudes & 3.99 & Often \\
\hline Composite Mean & 3.95 & Often \\
\hline
\end{tabular}

The perception of the immediate constituents perceived their Punong Barangay as competent organizers of which they have the ability to discover, understand and verbalize ideas, thoughts and concepts. They also perceived that the Punong Barangay are very competent leaders because they can direct, motivate and establishes rapport among subordinates. They also takes the initiatives of maintaining high standard. The Punong Barangay
Inter-personal skills are considerable high which implies that they maintain good relationship with peers and subordinates. They also exhibit tactfulness and diplomacy and can reconcile differences among interest groups. The punong Barangay also have strong resolve to further improve themselves on their job and have a strong tolerance for stress and can allocate time wisely.

Table 2

Weighted Mean Distribution of Responses of Punong Barangay on Leadership Behavior

\begin{tabular}{lcc}
\hline Leadership Behavior & Mean & Qualitative Description \\
\hline Supportive & 4.26 & Often \\
Achievement Oriented & 4.25 & Often \\
Directive & 4.20 & Often \\
Participative & 4.19 & Often \\
\hline Composite Mean & 4.23 & Often \\
\hline
\end{tabular}

In general, the Punong Barangay of Southern Nueva Vizcaya often practiced supportive, achievement oriented, directive and participative leadership behavior as drawn from the composite mean of 4.23 .

Of the four leadership behavior, the Punong Barangay rated themselves highest in supportive leadership behavior as evidenced by their mean response of 4.26 . The friendly and approachable nature of the respondents could be attributed to the fact that most the Punong Barangay are in the middle age. They consider their members as peers and not as subordinates.

As described by Greene (1988), supportive leaders look upon their task as not consulting with followers and considering their opinions but also doing all they can to support subordinates in accomplishing their duties. 
Table 3

Summary of F-test Comparing Leadership Behaviors of Barangay Captains According to Age

\begin{tabular}{lccc}
\hline Leadership Behavior & Computed F - ratio & Tabular F - ratio & Decision \\
\hline Supportive & .176 & 2.16 & Accept Ho \\
Achievement Oriented & 1.80 & 2.16 & Accept Ho \\
Directive & 1.60 & 2.16 & Accept Ho \\
Participative & .87 & 2.16 & Accept Ho \\
\hline
\end{tabular}

The Punong Barangay, whether young or old, do not differ in leadership behavior behavior. It could be inferred that both young and old Punong Barangays are supportive, achievement oriented, directive and participative. Further, they solicit opinions from their constituents, they involved everybody to a particular task, and they give support to all activities of the barangay.

Table 4

Summary of T-test Comparing Leadership Behaviors of Barangay Captains According to Sex

\begin{tabular}{lccc}
\hline Leadership Behavior & Computed T-ratio & Tabular T - ratio & Decision \\
\hline Supportive & 0.06 & 1.960 & Accept Ho \\
Achievement Oriented & 0.03 & 1.960 & Accept Ho \\
Directive & 0.09 & 1.960 & Accept Ho \\
Participative & 0.09 & 1.960 & Accept Ho \\
\hline
\end{tabular}

The Punong Barangays whether male or female are both effective administrators and do not differ in leadership behavior. It may, thus be inferred in this findings that sex is not a factor to effectively influence and convince subordinates to do or achieve a particular endevour. Further, it can be inferred that the male dominated political positions in the barangay can equally be executed by the female sex. Reasons among other could be, managing the affairs of the barangay does not require body strength but more on the intellectual capability of the leader.

Table 5

Summary of F-test Comparing Leadership Behaviors of Barangay Captains According to Civil status

\begin{tabular}{lccc}
\hline Leadership Behavior & Computed F - ratio & Tabular F - ratio & Decision \\
\hline Supportive & 0.5 & 19.49 & Accept Ho \\
Achievement Oriented & 0 & 19.49 & Accept Ho \\
Directive & 0.2 & 19.49 & Accept Ho \\
Participative & 0.67 & 19.49 & Accept Ho \\
\hline
\end{tabular}

The findings in this study revealed that Punong Barangays

whether married, separated or widowed do not differ in

leadership behavior.

Table 6

Summary of F-test Compairing Leadership Behaviors of Barangay Captains According to Educational Attainment

\begin{tabular}{lccc}
\hline Leadership Behavior & Computed F - ratio & Tabular F - ratio & Decision \\
\hline Supportive & 0 & 2.67 & Accept Ho \\
Achievement Oriented & 0.05 & 2.67 & Accept Ho \\
Directive & 0 & 2.67 & Accept Ho \\
Participative & 0.25 & 2.67 & Accept Ho \\
\hline
\end{tabular}

The findings revealed that there are no significant differences in the leadership behavior among Punong Barangays when grouped according to educational attainment. 
Table 7

Summary of F-test Compairing Leadership Behaviors of Barangay Captains According to Annual Income

\begin{tabular}{lccc}
\hline Leadership Behavior & Computed F - ratio & Tabular F - ratio & Decision \\
\hline Supportive & 0.4 & 3.05 & Accept Ho \\
Achievement Oriented & 0.17 & 3.05 & Accept Ho \\
Directive & 0.33 & 3.05 & Accept Ho \\
Participative & 2.85 & 3.05 & Accept Ho \\
\hline
\end{tabular}

The findings revealed that there are no significant differences in the leadership behavior among Punong Barangays when grouped according to monthly income. It could be done by people with low, average and high income and could be attributed to the fact that money is not a motivator for job performance. Leaders will work according to their duties and functions since they are expected by their constituent to take the lead for the growth and development of the organization.

\section{CONCLUSIONS}

Based on the findings of the study the following conclusions are therefore presented.

1. The Punong Barangays in the province of Nueva Vizcaya are predominantly male, married, about 45 years old, high school graduates and the mean annual income seems to be rather low if they are married with 5-9 dependents to feed and support for their education.

2. The competencies of Punong Barangays in the province of Nueva Vizcaya is very satisfactory as perceived by their immediate constituent

3. The leadership behavior of Punong Barangays in the province of Nueva Vizcaya is very satisfactory as perceived by themselves.

4. The leadership behavior of the Punong Barangays in the province of Nueva Vizcaya do not vary significantly when grouped according to age, sex, civil status, educational attainment and annual income.

\section{V.RECOMMENDATIONS}

Based on the findings and conclusions of the study conducted the following recommendations are therefore crafted and proposed.

1. Based on the findings, majority of the Punong Barangays reached or finished high school and it is therefore recommended that they may be encouraged to develop their reading habits as part of their informal education and training for personal growth and development. Government agencies like the Philippine Information Agency and the Department of Interior and
Local Government should periodically publish and furnish the Punong Barangays with barangay bulletins, newsletters, magazine and other printed materials designed to keep them abreast with current issued and trends.

2. Congress may consider the legislation of new salary measure and other monetary incentives for the Punong Barangay equal to other government workers with the same nature of job. These will give more encouragement and satisfaction, ensure competencies and imbibe a sense of responsibility.

3. Additional variables in the profile may be included in order to identify other variables that influence the respondents such as ethic affiliation, religion, seminars and trainings attended. Data coming from the constituents may be considered as part of assessing the respondents' leadership behavior in order to acquire comparative information about the research respondents.

4. Future researchers may replicate the same study using a wider scope of respondents in order to ascertain new concepts which may help the management and processes of barangay systems.

\section{WORK CITED}

1. Gree, Madeline F. Leaders for a New Era, London: Collier Mcmillan Publisher, 1988

2. Leveriza, Joe P. The Management Organization. Manila: National Book Store, 1986

3. Nolledo, Jose. Local Government Code of 1991 Annotated.

4. Ordonez. (2000). Leadership Behavior and Competencies of Sangguniang Kabataan from Province of Nueva Vizcaya

5. Tendero (1993), Theory and Practices of Public Administration in the Philippines

6. Punzalan and Uriarte (1987), Statistics. A simplified Approach

7. Stogdill. (1990). Handbook of leadership.

8. Sajo and Tabaldo. Local Executives' Perceptions and Initiatives. Philippine Journal of Public Administration, 1994 